\title{
Analysis on the Development Trend and Disadvantages of College English MOOC in the Information Age
}

\author{
Jie Gao \\ Jilin Institute of Chemical Technology \\ Jilin, China
}

\begin{abstract}
The ever-changing scientific technologies have greatly changed our teaching model and put forward higher requirements for English educators in the new era. In today's information age, English teaching is also facing qualitative changes, new forms of teaching are constantly emerging, and new teaching methods such as Microlecture and MOOC have developed rapidly in just a few years. In the information age, the advantages of "MOOC" are increasingly obvious, but there are also drawbacks. In the face of new challenges, teachers should constantly improve themselves to adapt to the new situation and make full use of information technology to achieve the best effects of English teaching.
\end{abstract}

Keywords-information technology; English teaching; MOOC; development trend; drawbacks

\section{INTRODUCTION}

With the development of technology, information technology has had a profound impact on English teaching and will play a more and more important role, which is inseparable from the development of the world. From the beginning of the construction of multimedia classrooms, to the discussion of the feasibility of online courses, to the gradual popularization of the terms such as "Microlecture" and "MOOC", China's teaching, especially English teaching, has continued to advance to new levels. It is not difficult to figure that the rapid development of information technology will definitely bring about qualitative reforms to English teaching. Just because we are still in the stage of change, we need to clearly understand that there are still problems that cannot be ignored to be solved by us, including the current shortcomings in the development of "MOOC" and the problem of corresponding changes in the minds of the educators.

\section{THE APPLICATION STATUS OF "MOOC" IN ENGLISH TEACHING}

\section{A. Research Methods and Data Analysis}

Through means of network data collection, literature search, field trips, university visits, questionnaires, interviews, etc., we have obtained a large amount of materials related to "MOOC", and had some understanding of the current application status of "MOOC" in the field of college English teaching in China.

From the perspective of the acceptance level of "MOOC", as a new thing, it was first welcomed by students. From university visits and questionnaires, through data collection and analysis, we found that more than $90 \%$ of students were positive about "MOOC", but less than $40 \%$ of teachers were willing to accept and participate in "MOOC". Most of the college students in the new era are willing to try new methods. Especially in today's information age, students' dependence on computers and mobile phones has been greatly improved, so the corresponding "MOOC" has become a form of teaching that students are willing to and easy to accept. For the teachers, this is a new challenge. After investigation, we found that the current degree of acceptance of the "MOOC" by the teachers was still low, but compared with teachers of other subjects, the acceptance rate of "MOOC" by English teachers is significantly higher than the average data.

From the perspective of the actual teaching effect of "MOOC", just as mentioned above, the "MOOC" has promoted students' learning of English, "MOOC" has obviously played an active role in improving students' English basic ability and application ability, providing good promotion effects for students' further improving their English level and English grades. Through questionnaires, interviews and other means, we have obtained a variety of data, and the content of the improvement effects of "MOOC" on English learning is the focus of our investigation. After data analysis, we found that the advantages of the "MOOC" considered by students mainly lied in the following aspects:

Firstly, "MOOC" provides students with more choices, so that they can fully feel the teaching styles of different teachers, learn and digest their advantages to choose the most suitable courses for their study, which undoubtedly has a great impetus to students' English study. Through online learning of different teacher courses, students not only broaden their horizons, but also can improve their English foundation and interest, playing a promoting role in daily learning.

Secondly, the freedom of choice of time and space alleviates the pressure of students' learning and enables 
students to arrange time more reasonably, fundamentally solving the problem that students can not be present on time, ensuring that students will not drop out of class, and avoiding the breakage of the time chain. No matter what subject, learning is a system. In many cases the knowledge points of the previous lesson and those of the latter lesson will have a certain convergence, so, if there is a knowledge gap, it is inevitably affect follow-up learning. The emergence of "MOOC" helps students avoid the knowledge gap and assists them to systematically master English knowledge, lay a good foundation, and steadily improve.

Thirdly, because "MOOC" is the content of the network, it can be suspended and replayed at any time, which provides convenience for the majority of students. In the traditional classroom, the progress of teaching is basically grasped by the teacher, but the progress of "MOOC" is grasped by the students themselves, which is also an advantage that most students appreciate very much.

Of course, these advantages, first of all, must be based on the serious implementation of "MOOC" if they want to make a difference. If teachers do things just in order to accomplish their tasks without due care, the effect will be greatly reduced.

\section{B. Future Development Trend}

The advent of the information age has changed the lives of each of us. Education informatization is an inevitable trend. It not only conforms to the historical trend, but also has practical application value. From the data we have obtained at present, in the future, the application of "MOOC" will be more and more extensive, not only covering more colleges and universities, but also entering more course types, including professional English teaching and non-professional English teaching, and teachers in the field of "MOOC" participation will be higher. According to the current data, we believe that "MOOC" will achieve real popularity and help students go faster and farther on the road of English learning.

At present, "MOOC" has broken away from the constraints of the computer, and the spreading way has been extended to mobile phones, tablets and other more convenient ways to further help students out of time and space constraints, but these ways also have technical limitations. It is believed that with the further development of science and technology, the restrictions will be further reduced, and the study of "MOOC" will be more convenient.

\section{CURRENT PROBLEMS AND BRIEF ANALYSIS}

In view of the present situation in all aspects, the development of English teaching in China still faces the following problems:

The first is the transformation of teachers' thinking. Although the group of English teachers in China has been developing towards younger age, a considerable number of English teachers are still at a higher age level, and these teachers tend to be more conservative and less receptive to new things. In addition, in the face of new information technology, due to the influx of a large number of new knowledge, some teachers will be confused, and then evade the use of them. Moreover, new knowledge, new technology will bring the workload to be enlarged in the early stage, which will also make some teachers have a certain degree of resistance. Besides that, unlike teaching in a single classroom, in the form of "MOOC", teachers are faced with students from all over the country, which is also a big challenge to the image of teachers and their ability to adjust themselves when facing the camera. This has led that some teachers, despite their high teaching level and rich teaching experience, but because of shots-defying and video recording-defying status, are reluctant to participate in the "MOOC". They are prone to be constrained by their poor image so that they dispute "MOOC", which imperceptibly results in that the overall level of "MOOC" has not reached its due height.

The second is the information technology level of teachers. Due to the rapid development of information technology, even if teachers want to master the technology, it is often difficult to achieve under the pressure of busy work. Consequently, the lack of mastery of information technology results in unsatisfactory use results.

The third problem is the discrimination and selfmanagement ability of students when they are confronted with abundant information materials. Although the rich learning content and various forms of expression brought by information technology contribute great convenience to students' English learning, it must be admitted that when faced with the complicated materials, the younger students often be diverted attention by some information not directly related to what they are learning at present, resulting in waste of time and information misleading.

The fourth one is the shallow level of information technology utilization. Even today, with the rapid development of science and technology, there are still many students who regard multimedia technology, network technology, distance courses and so on as supplements to the traditional teaching, thus focusing mainly on the traditional learning methods, paying little attention to the courseware, micro-lessons, MOOC etc. elaborately made by teachers. Some students even regard teaching videos watch, online homework completion just as tasks perfunctorily, and even that, some teachers also just think of information technology as formalism, but not attach importance of it enough.

\section{SOLUTIONS AND PROSPECTS}

To solve the problems mentioned above, we suggest teachers start from the following aspects:

The first is the transformation of teachers' thinking. For older English teachers, it is necessary to explain thoroughly the active effect of information technology on teaching and help them to change their thoughts. If it is difficult for them to accept new knowledge, special technicians can be sent to teach them information technology knowledge to help them master the information technology required for teaching. Universities can properly organize a competition in the teaching of information technology to encourage teachers to accept new things and technologies from the side. As for 
teacher's image or teacher's rejection of lens, relevant technicians can give the teacher the guidance on dressing and make-up, and assist teachers to relax their mind through good language and attitude, so that they can finish the recording of video successfully.

The second is the teacher's own information technology level. This point overlaps with the above one, that is, it can be solved by sending specialists to teach information technology knowledge for them. Moreover, universities can reasonably arrange the working hours of English teachers, reduce the workload of English teachers within the allowable scope, and schedule a fixed time for the transference of information technology knowledge, so as to provide favorable conditions for teachers to master the required information technology knowledge.

The third is the students' ability to discriminate information and manage them. For one thing, we should carry out ideological education for students to make them aware of the importance of online learning and off-campus learning; for another, we should further utilize cutting-edge information technology to minimize the likelihood that students will be able to browse the web at will and be attracted by other content. Furthermore, from a technical point of view, the relevant personnel can set the online video to a form that the video can be played in the active window rather than in the minimized window, and add functions such as asking the student to answer at any time.

Education in China has gradually matured after years of development and change. In the new era of "MOOC", we still face many challenges, but if we can use the method mentioned above to make up for the existing defects, the effect of English teaching will surely be further improved.

\section{CONCLUSION}

In the process of studying this issue, the author has collected a large amount of data and visited many universities to study, which guarantees the objectivity and accuracy of this study. Through data collection and data analysis, we find that although "MOOC" has many advantages, it also has some drawbacks, which poses new challenges for English educators in the new era. Only by deeply studying the current situation of English teaching in the form of "MOOC" can we better improve the teaching effect, further improve English teaching, and pave the way for future English education.

Due to the limited information, limited time, limited level of the author, and limited number of universities the author visited, this study cannot reach the level of perfection, and there are still many shortcomings at present, which will be further improved in future research.

\section{REFERENCES}

[1] Blake, R. New Trends in Using Technology in the Language Curriculum [J]. Annual Review of Applied Linguistics, 2007, 27(1).
[2] Kern, R., Ware, P. \& M. Warschauer. Crossing Frontiers: New Directions in Online Pedagogy and Research. [J]. Annual Review of Applied Linguistics, 2004 (24).

[3] Sun Yaoting, Chen Xin. Research on the Construction of Mobile Campus in Open University [J]. China Education Info, 2007 (10).

[4] Lan Bing. Study on Distance Foreign Language Teaching under Mobile Technology Environment [J]. Journal of Yunnan RTV University, 2009 (4).

[5] He Xiaojun, Guo Xuewen. The Establishment of Independent Learning Mode in English Learning [J]. Journal of Teaching and Management, 2010 (4).

[6] Wang Zengchang. Breakthrough in the Reform of English Teaching [J]. China Education Daily: Basic Education, 2000.

[7] Li Suzhi. Comparing Interaction Patterns in the Classes of Native English Teachers and Chinese Teachers [J]. Journal of PLA Foreign Language University, 2007 (2).

[8] Chen Jianlin. Integration of Computer and Internet into Foreign Language Teaching Program- A Study Based on the Reform of College English Teaching $[\mathrm{M}]$. Shanghai: Shanghai Foreign Language Education Press

[9] Cheng Dongyuan. Technology and Techniques in Teaching and Leaning Foreign Languages [M]. Beijing: National Defence Industry Press , 2008. 